\title{
Infecção cutânea por Brevibacillus brevis em paciente transplantado renal: Caso Clínico
}

\author{
Débora de Camargo 1; Caroline Haab 2; Bruno Tischler 3;Alexandre \\ Vargas Schwarzbold 4; Liliane Souto Pacheco 5; Priscila de Arruda \\ Trindade ${ }^{5}$
}

\section{Resumo}

INTRODUÇÃO: Brevibacillus brevis (B.brevis) é uma bactéria grampositiva, aeróbica, bacilo formador de esporos comumente encontrado no solo, ar, água e matéria em decomposição. Raramente associada à doenças infecciosas. Entretanto, pode acometer imunodeprimidos, devido à suscetibilidade destes. Nesse cenário, a correta identificação do agente etiológico é essencial. Métodos diagnósticos, que não dependam do crescimento do germe e que inclusive sejam efetivos quando os patógenos não estão viáveis, têm sido desenvolvidos como a tecnologia MALDI-TOF (Matrix Assisted Laser Desorption Ionization Time-of-Flight) que identifica rapidamente micro-organismos. OBJETIVO: Relatar caso raro de infecção por (B.brevis) em lesão ulcerada de paciente imunodeprimido. Pretende-se também apresentar a técnica de MALDI-TOF como instrumento importante para detectar rapidamente germes raros. DESCRIÇÃO): Paciente imunodeprimido por transplante renal em uso de imunossupressores.Interna com quadro de infecção de partes moles e pele,apresentando quadro febril e lesão ulcerada de membros inferiores, ausência de resposta antimicrobiana empírica e guiada por cultura.Obteve-se novos culturais de biópsia da lesão

\footnotetext{
${ }^{1}$ Apresentadora. Acadêmica de Medicina, Universidade Federal de Santa Maria. E-mail: debora88camargo@gmail.com

${ }^{2}$ Acadêmica de Medicina, Universidade Federal de Santa Maria. E-mail: carol haab@hotmail.com

${ }^{3}$ Acadêmico de Medicina, Universidade Federal de Santa Maria.

${ }^{4}$ Orientador. Doutor em Ciências Médicas pela UFRGS. Professor de Medicina na disciplina de Doenças Infecciosas na Universidade Federal de Santa Maria. Médico Infectologista da Comissão de Controle de Infecção Hospitalar e Chefe do Setor de Pesquisa e Inovação Tecnológica do Hospital Universitário de Santa Maria. E-mail: alexvspoa@gmail.com

${ }^{5}$ Médica Infectologista no Hospital Universitário de Santa Maria.

${ }^{6}$ Professora da Farmácia na Universidade Federal de Santa Maria.
} 
identificando-se bacilo gram-positivo sem identificação de gênero e espécie.Posteriormente, enviou-se o material de cultura para realização do MALDI-TOF,visando uma melhor identificação etiológica.Assim,chegouse ao diagnóstico de infecção por (B.brevis).Dado não existir antibiograma, fez-se o tratamento empírico voltado ao germe específico baseado nos poucos dados de literatura existentes.Paciente evoluiu com melhora importante da lesão sem necessidade de redução da dose de imunossupressores. CONCLUSÃO: MALDI-TOF é um método de espectrometria de massa, permitindo a ionização de macromoléculas biológicas, mediante à absorção de feixes de laser. Tal metodologia identifica rapidamente e com precisão uma grande diversidade de gêneros e espécies de bactérias através da comparação do espectro bacteriano com os dados existentes em um grande banco de dados. Devido à complexidade de determinados tipos de infecção, é importante que o agente etiológico seja identificado precocemente, visando o tratamento específico que reduz mortalidade. Ainda que culturas sejam métodos úteis na recuperação de patógenos, em alguns casos podem ter o resultado tardio. Diante disso, o MALDI-TOF é uma alternativa na identificação precoce da etiologia de uma infecção, permitindo a redução no tempo de hospitalização.

Palavras Chave: transplante renal; imunossupressão; Brevibacillus brevis. 
